JOSÉ MARÍA HERNÁNDEZ DÍAZ (COORD.)

\title{
INFLUENCIAS SUIZAS EN LA EDUCACIÓN ESPAÑOLA E IBEROAMERICANA
}
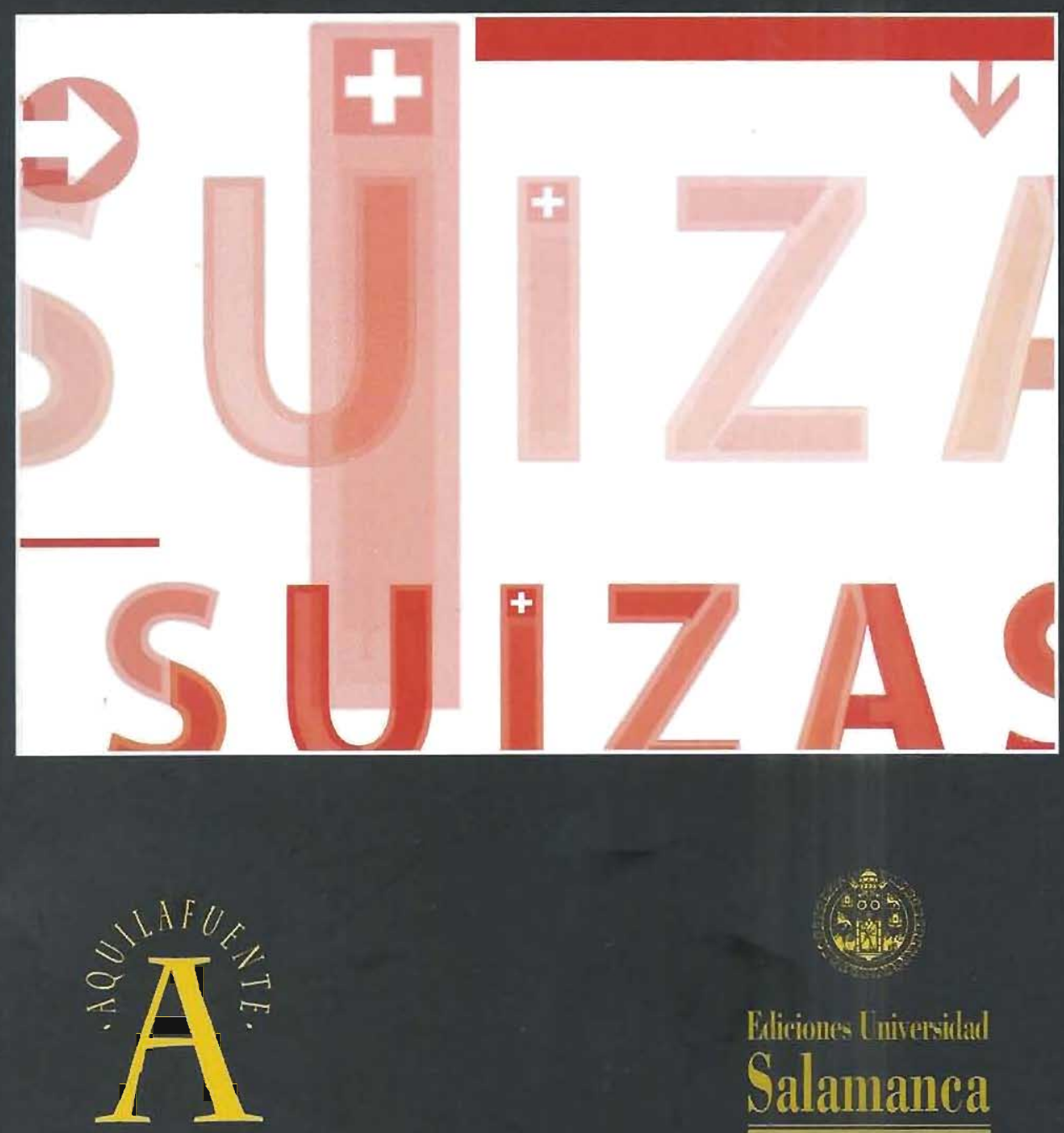

Ealiciones Lniversilad Salamanca 
AQUILAFUENTE, 225

(c)

Ediciones Universidad de Salamanca

y los autores

Imagen de cubierta:

Carmen González Martín

$1^{a}$ edición: octubre, 2016

ISBN: 978-84-9012-657-8

Depósito legal: S. 461-2016

Ediciones Universidad de Salamanca

Plaza San Benito s/n

E-37002 Salamanca (España)

http://www.eusal.es

eus@usal.es

Impreso en España-Printed in Spain

Diseño, edición y composición:

Alexia Cachazo Vasallo

Impresión y encuadernación:

Nueva Graficesa, S.L.

www.graficesa.com

Salamanca (España)

Impreso en España - Printed in Spain

Todos los derechos reservados.

Ni la totalidad ni parte de este libro

puede reproducirse ni transmitirse sin permiso escrito de

Ediciones Universidad de Salamanca.

Ediciones Universidad de Salamanca es miembro de la UNE

Unión de Editoriales Universitarias Españolas

www.une.es

CEP. Servicio de Bibliotecas

INFLUENCIAS suizas en la educación española e iberoamericana / José María Hernández Díaz lcoordinador].

-1a. ed.-Salamanca : Ediciones Universidad de Salamanca, 2016

520 p.--(Colección Aquilafuente ; 225)

Textos en español y portugués

1. Educación-España-Influencia suiza. 2. Educación-Portugal-Influencia suiza.

3. Educación-América Latina-Influencia suiza. 4. Educación-Suiza-Influencia.

I. Hernández Díaz, José Maria, 1951-, editor.

37(460):37(494)

37(469):37(494)

$37(72 / 729)(8): 37(494)$ 


\title{
O PROFESSOR NO OLHAR DE ADOLPHE FERRIÈRE - UMA LEITURA CONTEMPORÂNEA
}

\author{
Evangelina Bonifácio \\ evangelina@ipb.pt \\ Escola Superior de Educação de Bragança
}

\section{INTRODUÇĀO}

A escolha do livro «A Escola por Medida pelo Molde do Professob) relaciona-se com o impacto e curiosidade que o nome da obra suscitou considerando a minha opção por uma linha de investigação em torno da temática professores e escolas. Desde logo o título parecia situar-se e sintetizar essa matriz investigativa. Nesse sentido, procurei fazer uma leitura global do livro centrando-me na relevância que Adolphe Ferriète atribuia ao professor. Advogava que "dominada a educação dos futuros educadores, terá de ser colocada a cultura da sua personalidade, potque, mais do que nunca, - e bem mais, com os métodos chamados novos - qual mestre, tal escola" (Ferrière, 1934, p. 37).

\section{BREVES NOTAS SOBRE O AUTOR}

Adolphe Ferrière foi um destacado pedagogo suíço e um dos nomes eloquentes do Movimento da Educação Nova (30 de Agosto de 1879 - 16 de Junho de 1960 - Genebra). Do muito que haveria para salientar, recorda-se que foi membro fundador do Bureau International d Éducation Nourelle (1899), um dos fundadores, do Instinuto Jean-Jacques Rousseau (1912), em Genève e, além do mais, colkborou na criação da (Ligue Internacional pour l"Éducation Nouvelles quando, em 1921, se encontrava em Calais-França, no decurso do I Congresso Internacional da Educação Nova. Da sua obra destacam-se livros como: Transformons IÉcole. Appel aux parents et aux autorités (1920), L École Active (1927), L'École Sur Mesure à la Mesure du Maître (1931), entre outros.

\section{A OBRA EM (RE) LEITURA}

Trata-se de um livro editado em Portugal em $1934^{1}$ e encontra-se dividido em duas partes. A I parte, o autor, chamou-lhe 〈parte critica - exposisaro documentadan e trata temas como: a escola por medida, o molde do professor, o sistema de programas

1 Tradução de Vítor Hugo Antunes, do original L'École Sur Mesure à la Mesure du Maître (1931). De referir que as citações encontradas, ao longo deste texto, respeiram a ortografia usada na época. 
múltiplos, a nova criança, a escola serena, o professor da escola nova e a personalidade do professor.

Relativamente ao ponto I (escola por medida) inicia com a ideia de que este título para a escola é justo porquanto sendo cada criança diferente da outra a escola limitase, quase só, ao ensino coletivo. Porém, sublinha que quando os professores ouviam esta expressão era legítimo que questionassem: "Serão precisos, então, tantos professores quantos os alunos?" (Ferrière, 1934, p. 6). Ironiza dizendo que não! Adianta que talvez sejam necessários tantos métodos quantos os alunos, porque a cada tipo de criança convém um determinado método e todos eles são aspetos parciais da escola ativa. Escreveu que "sobretudo, cada um, é o que melhor convém ... a quem o criou!"” (Ferrière, 1934, p. 7).

No ponto II (o molde do professor) admite que esta expressão provocava um sorriso de inteligência no rosto dos seus interlocutores, emergindo a alegação "escolherei então o que mais me convier! Que responder-lhes? 'Tinham razão, inteira razão! Cada um de nós, adultos, só dá o máximo de que é capaz - em qualquer profissão - quando ela corresponde às suas aptidões" (Ferrière, 1934, p. 8). Nesta linha de pensamento, defende a necessidade de formação de professores, sustentando que ensinamos como nos ensinaram e, por isso, seria necessário passar de um saber-erudição para um saber-aptidão, dando ao professor a possibilidade de trabalhar as suas ideias.

No ponto III (o sistema dos programas múltiplos) refere várias experiências de outros países em que se utilizavarn os métodos modernos. Todavia reconhece a falta de latitude na sua aplicação, bem como a escassa maleabilidade de alguns docentes para se adaptarem sublinhando que "o professor não é "moderno" só porque leu - e, talvez, mal compreendeu - dois ou três livros" sobre a escola ativa, referindo que da teoria à prática, tal como da compreensão à ação vai uma enorme distância (Ferrière, 1934, p. 14).

No ponto IV (a nova criança) evidencia que antes de estudar a ação do professor é necessário atender ao desenvolvimento e contributos das ciências como a psicologia, a fisiologia e a medicina, visando o interesse da criança. Recordando uma palestra de Maria Montessori, em Paris, em 02 de abril de 1931, corrobora as suas palavras e concorda que os problemas da educação decorrem da ideia de que o adulto é o todo-poderoso, que domina a criança e a impede de se desenvolver; pretendendo dirigi-la de acordo com as suas conviçções e ideias pré-concebidas. Salienta que o professor deve preparar à criança "uma ambiência desembaraçada de obstáculos (...) determinada pelas necessidades naturais e legítimas exigèncias durma única pessoa - a criança - que sem necessidade de lutar contra obstáculos, começara, pouco a pouco, a manifestar as suas faculdades superiores (...) criadoras duma personalidade nova" (Ferrière, 1934, p. 19).

No ponto $V$ (a escola serena) refere que esta é uma tentativa de escola nova, baseada no valor da sugestão lenta da escola, em liberdade, autoeducação c respeito pelo valor da individualidade. Acrescenta que através dos castigos, da imposição, do autoritarismo se pode obter: ordem mas não a disciplina interior. No seu entender, este clima escolar é impossível nas escolas em que o professor for o depositário da ciência e a "distribuir, em porções mínimas, previamente pesadas e cuidadosamente calculadas, fazendo-as acompanhar ainda de longos discursos" (Ferrière, 1934, p. 24).

No ponto VI (o professor da escola nova) defende que ser educador-professor é exercer uma das mais tentadoras, venturosas e agradáveis profissões, contribuindo 
para isso os métodos novos que procuran o interesse e a colaboração da criança, na ação educadora do docente. Explicita, a partir do testemunho de pedagogos e investigadores, que devem ser substituidos os professores que ensinam pelos que "ajudam a estudar, os que impõem pelos que dão o exemplo e ajudam a realizar, os que reprimem pelos que inspiram (Ferrière, 1934, p. 32).

No ponto VII (a personalidade do professor) sustenta o valor da pessoa do professor - qual mestre, tal escola - e refere a importância da moralidade e dos seus princípios éticos e deontológicos não, simplesmente, pelo seu conhecimento abstrato, mas pela forma como este os integra na sua personalidade e na sua humanidade. $\mathrm{Na}$ rra um exemplo curioso, traduzido na troca de palavras entre uma mãe e o professor de determinada localidade. Em jeito de desabafo esta comentava que os alunos estavam bastante mais delicados desde que ele era professor na escola da aldeia. Todavia o professor nunca ensinou civilidade. "Era naturalmente delicado, sem a preocupação de o ser; e a sua urbanidade tinha, por assim dizer, irradiado, e de certa forma, contagiado os alunos (...) subjugados pelo ambiente!" (Ferrière, 1934, p. 40).

$\mathrm{Na}$ II parte, intitulada de (parte construtiva - como se põe o problema» o autor refere-se a várias questões como: a escola como instrumento do professor, o obstáculo dos exames, programas e horários, métodos antigos e novos, a reforma pedagógica, o professor novo, a escola pública renovada, os diversos programas, para uma melhor preparação do corpo docente e realizações em matéria de legislação escolar, como veremos de seguida.

Assim, em continuação no ponto VIII (a escola como instrumento do professor) inicia afirmando que quer adultos quer crianças têm diferentes competências e cada um deve centrar-se para dar o seu «optimumm. Sublinha que o indivíduo evolui num contexto onde existem elementos favoráveis ou desfavoráveis. Nesta linha de pensamento, evidencia que certos elementos são inalteráveis (clima, atmosfera social); outros são dificilmente transformáveis (ação dos pais); outros são perfectíveis (leis escolares). Alude à importância da legislação escolar como garantia de que ninguém se mostrará inferior à sua missão, partindo de um mínimo de condições "derivadas da ciência e também das necessidades da nação e da humanidade" (Ferrière, 1934, p. 50). Acrescenta que a escola, desse tempo, tinha imperfeições porque era vítima de legisladores desatualizados, apontando sugestões legislativas. Acredita que a escola pública renovada, só acontecerá com uma melhor preparação de professores e programas variados. Em traços getais defende que a legislação funciona como garantia pública que visa, além do mais, facilitar a missão do professor

No ponto IX (o obstáculo dos exames) sustenta que os tradicionais exames näo devem ser fator determinante nas escolhas futuras. Destaca que estes não definem as competências de cada um favorecendo "a memónia superficial - a que suscita instantâneamente as respostas a preguntas imprevistas. Favorecem o raciocínio ensinado, e não a arte de raciocinar com prosperidade" (Ferrière, 1934, p. 58).

No ponto X (programas e horários) explicita a ideia de que os programas não tinham em conta os interesses das ctianças, separando o saber em tamos (entendidos como o conhecimento da natureza, a humanidade, o tempo e o espaço) e a que falta um uronco (entendido como atualidade). Nesse sentido propõe um programa mínimo (obrigatório para todos) e um programa impresso que inclua uma variedade de assuntos possiveis em que se evidenciem os que são propostos tratar e se eliminem os que 
já foram tratados. Quanto aos horários realça que, muito divididos, originam perda de tempo e de esforços pelo que se deveriam concentrar, apontando boas experiências educativas já testadas nesse sentido (escolas novas de Hof-Oberkirch - Suiça, Odenwald - Alemanha e a escola primária M.me Boschetti-Alberti - Agno, Tessino - Suíça).

No ponto XI (métodos antigos e novos) sugere que os métodos sejam alterados considerando a psicologia da criança, no sentido de favorecer o seu desenvolvimento autónomo. Escreveu que a 'Tição - a antiga lição - em que só o professor fala e interroga - está condenada há muito. Mas, ainda com muita frequência, se vê sucederemse exposiçôes doutrinátrias (....) que não estabelecem "uma ponte entre a mentalidade simplista e a complexidade da vida" que não correspondem, aos interesses e curiosidade dos alunos (Ferrière, 1934, pp. 69-73).

No ponto XII (a reforma pedagógica) o autor realça os avanços científicos (psicologia, biologia, sociologia) referindo que estes obrigam a que se façam reformas, devendo conservar da tradição o que está bem e evitar, igualmente, inovações arriscadas. Todavia, relembra a necessidade de revisão dos métodos e práticas de acordo com as novas descobertas das ciências teóricas. Inventaria os contributos da psicologia genética, descritos em nove pontos, que consideta incontestáveis, sendo que a escola nova se deve alicerçar nesses postulados. Em seu entender; estes permitiriam compreender que o improviso é inadmissível no contexto escolar. Expressa que "são necessários, portanto, escolas modelos. ¿Mas com que professores? Haja escolas normais com métodos novos. Preparem-se professores especializados para elas. Sancione e favoreça a lei a educação nova. Que os especialistas estejam sempre a par dos progressos da ciência, como é indispensável" (Fertière, 1934, p. 82). Igualmente aponta caminhos e reforça a importância da formação de professores, chegando a classificá-los em professores antigos não aperfeiçoados, professores antigos (com diploma de aperfeiçoamento) e professores novos (saídos das escolas normais).

No ponto XIII (o professor novo) acentua a ideia de que o eixo da escola está na personalidade do professor, daí a importância do seu papel e da sua formação. Refere estes dois âmbitos de forma detalhada, bem como elenca as vantagens do professor novo afirmando que da sua excelência técnica e do seu valor moral dependem o homem e a humanidade.

No ponto XIV (a escola pública renovada) recorda os passos a dar (conhecer o avanço da ciência, promulgar a reforma escolar, selecionar e formar o professor da escola nova) e sugere uma nova organização escolar para a escola pública. Recorre às ideias de Lorenzo Luzuriaga, transcrevendo pontos de legislação, que possibilitariam renovar a escola (organização, vida intelectual, organização de estudos, educação social, educação artística e moral).

No ponto XV (os diversos programas) indica para a escola pública renovada dois programas (o mínimo e o de desenvolvimento) explicando como seria possível a sua conceçăo. De modo sintético, o programa mínimo resultaria do acordo de psicólogos, economistas, professores (conjunto de considerações de ordem genética, sucessão do tempo, história do trabalho e relação entre fenómenos - biológicos, físicos, económicos e humanos). O programá de desenvolvimento, na escola ativa, deveria incluir quatro escalōes - escola do trabalho, centros de interesse, escola ativa, escola serena - bem como a preparação de professores. 
No ponto XVI (para uma melhor preparação do corpo docente) defende uma formação de professores de acordo com as novas missões e complexidades da escola. Tal como já referido, sublinhou "que para melhorar a escola, forçoso é melhorar o professor" (Ferrière, 1934, p. 119). A partir de outros trabalhos propõe formas de seleção e formação docente explanando que "o professor - se quisermos assegurar a vida normal e os progtessos da democracia - deve vir à Universidade familiarizar-se com as novas disciplinas (...) psicologia da criança, antropologia (...) ciência social" (Ferrière, 1934, pp. 123-124).

No ponto XVII (realização em matéria de legislação escolar) elenca vários exemplos de boas práticas vertidas em leis escolares, como a de aAbel Miroglio» de 1929, transcrevendo-a da revista «Foi et Vie» ( $\mathrm{n}^{\circ} 16$ - outubro), entre outras. Assume que seriam a fórmula para favorecer e transformar a escola pública.

Termina com as conclusões em que sintetiza e menciona algumas soluções para renovar (transformar) a escola fazendo depender essa mudança de uma melhor preparação dos docentes do futuro. Assim, sugere que estes frequentem cursos de aperfeiçoamento, em tempo de férias, no Instituto de Ciências da Educação de Genebra. Porém, não havendo essa possibilidade, era importante permitir a sua deslocação ao estrangeiro para os colocar em contacto com diferentes métodos e "estudá-los in loco durante um ano ou dois, para viretn depois ensiná-los aos professores sứços" (Ferrière, 1934, p. 144).

Numa leitura reflexiva da obra, verifica-se a abordagem de várias questões em torno da escola e dos professores. Todavia, é certo que estas expressam um novo pensamento pedagógico, cujo objetivo seria urna educação mais autónoma, mais consciencializadora e mais centrada na singularidade humana. No entanto, este autor destaca, continuadamente, a importância da pessoa do professor e da sua formação fazendo reflexões em torno de uma questão principal: "¿Porque nos preocupamos com as aptidões do aluno e não com as do professor?" (Ferrière, 1934, p. 9). Reconhecendo a intemporalidade da questão e considerando que a qualidade da formação docente permanece como um desafio, na escola do século XXI, optou-se por evidenciar o pensamento do autor sobre o (professor novo».

\section{O professor no olhar de Adolphe Ferriere}

As referências, nesta obra, aos professores são demasiado evidentes em todo o texto. Existem inúmeras reflexões em torno da ideia e da importância do professor (papel, formação, personalidade). Igualmente há capítulos, inteiramente, dedicados aos professores como é o caso do Capítulo II, VI, VII, VIII e XIII e XVI, cujos títulos recorda-se são, respetivamente, a escola como molde do professor, o professor da escola nova, a personalidade do professor, a escola como instrumento do professor, o professor novo e para uma melhor preparação do corpo docente, respetivamente. Porém, o capítulo que se pretende evidenciar com maior detalhe serä o uprofessor novo" por se entender que nele se encontram aspetos relevantes e que contribuíram para a reflexão pedagógica sobre o professor enquanto profissional de educação. Ora, aqui o autor inicia com uma ideia marcante referindo que o "eixo da escola está na personalidade do professor. Disto resulta a importância do seu papel - e da sua formação" (Ferrière, 1934, p. 84). Além do mais, considera três elementos decisivos no processo educativo (as crianças, os processos pedagógicos e os professores). No 
último caso, acrescenta que os docentes, em quase todo o mundo, têm uma tarefa sobre-humana pois têm que enfrentar os preconceitos sobre o professor, oriundos na idade média, bem como os horários fixos, processos pedagógicos rígidos, regime autoritário, entre outras dificuldades. Na mesma linha de sentido, questiona: Como preparar o professor novo? Propõe três requisitos:

$1^{\circ}$ - Seleção prévia = o self-govermment escolar - entre os 9 e os 12 anos deveriam ser observados os alunos que demonstrassem capacidades para dirigir outras crianças, permitindo-lhes experienciar (treinar) essas competências;

$2^{\circ}$ - Cultura geral - entre os 12 e os 16 anos deveriam frequentar a escola primátia superior, um colégio ou um instituto preparatório. Defende que sejam selecionados os mais destacados para trabalharem com outras crianças, ambicionando que a escola fosse para estas idades uma escola ativa prática. Prolonga a sua narrativa, aludindo à importância de promover a entrada na profissão, em maioria, para os «tipos intuitivos» e, em minoria, para os «tipos imitativos»;

$3^{\circ}$ - Cultura especializada - depois entre os 16 e os 20 anos deveriam prosseguir a formação em escolas normais. Porém, admite como «aspiração» a sua preparação de nível universitário, pois sublinha que vão se deveriam colocar na prática professores sem conhecimentos psicológicos de nível superior. Reconhecendo esta necessidade assume, também, que não propõe tal solução porque há problemas de ordem financeira. Por outro lado, a universidade sofre de verbalismo (anotar apontamentos, estudá-los, recitá-los no exame) e, porventura, estes hábitos de "estudantes deformados por doze anos de escola, mais ou menos abstracta" não constitui uma forma adequada de formação docente (Ferrière, 1934, p. 86). Ainda, neste ponto, faz outras sugestões, realçando escolas como bons exemplos entre elas o Instituto Pedagógico de Viena, o Instituto Universitário de Ciências da Educação de Genebra e o Teachers College de Nova Iorque. A este propósito lembra que estas utilizam vários métodos como a observação, os inquéritos e os testes, congratulando-se com o facto destes não incidiram, apenas, sobre a capacidade de memorização.

Relembra, ainda, que o professor do futuro deverá ir além das teorias abstratas, da escola tradicional, e antes de ter o direito de ensinar deverá ter a oportunidade de experienciar na escola normal o modelo de formação que ele havia introduzido na Escola Internacional de Genebra que incluía:

O trabalho padrão-individual tendo por objeto as «técnicas» (cálculo, língua, etc);

O trabalho coletivo organizado em centros de interesse (atualidades, visitas a empresas agrícolas e industriais, visitas a serviços públicos ou instituições sociais, bem como centros de interesse local ligados a trabalhos próprios das estações e das necessidades do homem);

O trabalbo individual lime (investigação e coordenação de pequenas conferências aos pais e colegas, etc.);

O trabalho coletivo liver, nomeadamente trabalhos manuais (resolvidos em comum), excursōes históricas ou pedagógicas, espetáculos, exposições, etc.).

Em síntese, considerava insuficiente a formação de professores e defendia, tal como anteriormente explicitado, que "para melhotar a escola, forçoso é melhorar o professor" (Ferrière, 1934, p. 119). Por outro lado assinalou que os exames de admissão, às escolas normais, eram superficiais e deveriam ser re(pensados) através de novos métodos da escola ativa, elevando o nível de cultura geral dos candidatos à docência. Entre as suas 
propostas destaca-se, ainda, a criação de estágios (duração de um ano e meio), cursos universitários obrigatónios e a supressão de exames à saída dos cursos. Além do mais, sustenta que se durante o estágio, na escola (modelo e moderna) os futuros pedagogos revelarem competências ajustadas devem seguir cursos especiais de apenfeiçoamento na Universidade (com a duração de dois semestres). Aơvogava a ideia de que a escola normal ensirava o que era necessário ensinar e a universidade ensinava como se deveria ensinar. A partir das palavras de outros autores salientou várias ideias que testemunham a sua preocupação sobre a questão formativa, nomeadamente:

"queremos impor o respeito, fazendo a prova do nosso valor. Temos necessidade dum máximo de consideração para termos o máximo de influência sobre as gerações que educarmos (...) os primeiros interessados, os próprios professores, que com os seus alunos sofrem as consequências do deficit de preparação que receberam, são unânimes em pedir uma reforma completa da sua culrura profissional (...) os professores compreendem a sua responsabilidade (...) reclamam, a-fim-de aperfeiçoar esta mocidade e para a poder restituir melhor à sociedade, uma preparação profissional adequada às exigências das suas funções (...) a formação do pessoal docente primário reveste uma imporância tal, para o fururo do país, que devem ser envidados esforços imediatos para a romar melhor" (Ferrière, 1934, pp. 122-123).

$\mathrm{Na}$ mesma linha de pensamento, relembra o muito que há por fazer e propõe, como solução, que se reúnam os problemas relativos à formação de professores num todo que compreenda "a cultura da sua personalidade; a sua preparação largamente humana; o ensino duma psicologia indiscutivel, que lhe permita dar conta do que é a infância $(. .$.$) e que o familiarize com as técnicas mais eficazes e mais experimentadas$ da educação nova" (Ferrière, 1934, pp. 128-129).

\section{CONSIDERAÇÕES FINAIS}

$\mathrm{Da}$ leitura deste livro ressaltam novas ideias pedagógicas, radutoras de um novo sentido para transformar a escola de inícios do Século XX Pretendeu-se, contudo, destacar a preocupação manifestada por Adolphe Ferrière no que concerne à personalidade do professor e à sua formação. Sustenta que o "eixo da escola está na personalidade do professor. Disto resulta a imensa importância do seu papel - e da sua formação" (p. 84). Alicerça-se em pedagogos, seus contemporâneos, dos quais mobilizou experiencias educativas que iam sendo desenvolvidas e que, ao longo da narrativa, vai transcrevendo e realçando como boas práticas (Montessori-Itália; Método Paganini - Escola Renovada de Milão, entre outras). Já na conclusão deste livro sugere a necessidade de considerar, na educação nova, uma "quádiupla constelação» em que:

i.) Se respeite a criança e as etapas do seu desenvolvimento genérico;

ii.) Se considere a sociedade contemporànea e os seus interesses atuais (avião, rádio, progresso social, etc.);

iii.) Se valorizem as competências e as necessidades do professor (tendo como base a sua atividade intelectual, social e pedagógica);

iv.) Se adotem os recursos de que a ciência e a prática pedagógica contcmporâneas dispõem, no sentido de favorecer as qualidades do professor e do aluno.

Ressalve-se, todavia, que estas ideias começam a ser difundidas no início do século XX e, com alguma premência, emergem novos vocábulos educativos que, manifestamente, expressavam a rutura com os princípios da escola tradicional. Na época ganha espaço o Movimento Pedagógico da Escola Nova. A este propósito Alves (2010) refere 
que surgem nesse tempo

"importantes alterações políticas, iniciativas inovadoras de alguns movimentos (por exemplo de pedagogos, de professores ou de "cientistas da educação") ou propostas individuais (...). Surgem intelectuais que dão consistência a um pensamento pedagógico que privilegia a individualidade da criança em detrimento da homogeneizaçăo: americanos Dewey e Hall, europeus Montessori, Decroly, Biner, Kerchensteiner, Claparède, Ferrière, Faria de Vasconcelos e Adolfo Lima" (pp. 167-168).

Na mesma linha de reflexão, este autor, refere ainda a importância desta dinâmica pedagógica que desencadeia um conjunto de princípios que etam, em seu entender

"referèncias para marcar um ourro ritmo e um outro senúdo para o papel da escola. Não podemos ignorar, no entanto, que são estas iniciativas pioneiras que testam a "bondade" e a "exequibilidade" das inovações e é também nestas tentativas que a pedagogia se transforma num espaço experimental de aprendizagem. Neste sentido, fica una úlama nota para evidenciar alguns nomes e exemplos portugueses que procuraram ser agentes e exemplos de mudança. Entre os nomes destacariamos: Faria de Vasconcelos, Adolfo Lima, Pedro José da Cunha, Emilio Cosra, Afonso Duarte, Tomás da Fonseca, Aurélio Quintanilha, António Sérgio, Adelaide Cabete, Costa Ferreira, Agostinho de Campos, Adolfo Coelho, João de Barros, Palyart Ferreira, Alfredo Bensaúde, Alves dos Santos e Marques Leiño (...). Como se torna evidente, o Portugal republicano dos inicios do século XX estava claramente na linha do pioneirismo pedagógico e educarivo (Alves, 2010, pp. 171-172).

Ora, estes fundamentos confirmam que as novas ideias pedagógicas ultrapassaram fronteiras e tiveram, como é óbvio repercussão em Portugal, sendo referências que permitiram mapear e influenciar a profissionalização docente, com destaque para os professores primários. No caso português, as escolas normais "existiam desde meados do Século XIX" (Nóvoa, 1987, p. 426). Todavia, é a parir da Reforma de 1901 que a obtenção do diploma para exercer, no ensino primário, passa a ter carácter obrigatório. Esta medida teve impacto na sua profissionalização precoce, tendo sido pioneiro na exigência deste requisito e na criação de um forte movimento associativo, marcado pela realização de congressos pedagógicos (Nóvoa, 1987).

Relativamente aos contributos de Adolphe Ferrière, uma figura expressiva da Escola Nova, são conhecidas as suas ligações aos pedagogos portugueses que marcaram o ensino e a formação de professores em Portugal. Como exemplo menciona-se Faria Vasconcelos, António Sérgio, Adolfo Lima, entre outros.

Quanto a Faria de Vasconcelos recorda-se que foi o fundador e diretor da Écolle Nouvelle de Bierges - Bélgica, onde aplicou os princípios e dinâmicas da Educação Nova, no início do século XX. O seu livro «Une École Nouvelle en Bélgique» foi prefaciado por Ferrière, cm 1915 e nele redatou, primeiramente, os 30 pontos da Educação Nova ${ }^{2}$ Relativamente a António Sérgio, salienta-se que realizou os seus estudos de pósgraduação, entre os anos de 1914-16, no Instituto Jean-Jacques Rousseau, reconhecido como um centro mundial do Movimento da Escola Nova. Ora, Adolphe Ferrière foi um dos fundadores desta instituição e, por diferentes circunstâncias, privaram de modo próximo, mantendo relações pessoais e intelectuais. António Sérgio foi, também, o tradutor de algumas das suas obtas, situações em que o apelidou de rapóstolo da educação novar. De ressaltar que este pedagogo português foi um dos participantes do projeto de reforma do Ensino Português (Lei Camoesas) ${ }^{3}$, da autoria de João Camoesas e, pouco

2 Esta obra foi traduzida numa edição em português por Carlos Meireles-Coelho (2015).

3 Para mais informação consultar Casulo (2009). 
tempo depois, veio a ser nomeado Ministro da Instrução Pública, durante a $1^{2}$ República (18-12-1923 - 26-02-1924). No que se refere a Adolfo Lima, lembra-se que era advogado mas optou pela docência, ingressando na Escola Oficina $n^{\circ} 1$ de Lisboa, que ajudou a transformar numa referência da Educação Nova em Portugal. Foi diretor na Escola Normal de Lisboa e diretor da Biblioteca - Museu do Ensino Primário, entre outras atividades. A propósito, deste último cargo evidenciado, relembra Mogarro (2006), que a referida instituição foi instalada na Escola do Magistério Primário de Lisboa tornandose na instituição herdeira das antigas Escolas Normais da capital portuguesa. "Para seu director foi nomeado (...) Adolfo Lima (1874-1943), professor da mesma escola, que ocupou o cargo durante uma década e deixou o seu nome ligado ao periodo mais significativo desta biblioteca" (p. 6510). Ora, as referências apresentadas testemunham a proximidade intelectual destes pensadores portugueses, quer a Adolphe Ferrière, quer ao Movimento Pedagógico da Educação Nova, cujas ideias tiveram uma importância decisiva no processo de profissionalização da atividade docente em Portugal. A este propósito Nóvoa (1987) acrescenta que "ninguém pode escapar à sua "contaminação» e a definição dos professores como profissionais passará pela adesão aos princípios da Educação Nova" (p. 433).

Regista-se que, além das ascendências pedagógicas destacadas neste texto, Adolphe Ferrière visitou Portugal, em 1930, tendo sido recebido pelo Ministro da Instrução Pública, Gustavo Cordeiro Ramos, facto que the valeu fortes críticas na imprensa conservadora desse tempo.

\section{BibLIOGRAFIA}

Arves, L. A. (2010). República e Educação: Dos Princípios da Escola Nova ao Manifesto dos Pioneiros. Revista da Faculdade de Letras do Porzo - História, 11 - III Série, pp. 165-180.

Eerriere, A. (1934). A Escola Por Medida Pelo Molde do Professor. Porto: Editora Educação Nacional.

Meireles-Coelho, C. (2015). Uma Escola Nova na Bélgica. Aveiro: Universidade de Aveiro.

Mogarro, M. J. (2006). Bibliotecas Para Formacão de Professores em Portugal (1930-1970). Obtido em 22 de julho de 2016, de http://www2.faced.utu.br/colubhe06/anais/ arquivos/588MariajMogarro_Bibl.pdf.

Casulo, J. C. (2009). A Educação Superior no Projecto Camoesas. In B. Silva (Org.), Actas do Congresso Intemacional Galego-Pontuguês de Psicopedagogia. 10. Braga: Universidade do Minho. Obtido em 28 de julho de 2016, de http://repositorium.sdum.uminho.pt / handle/1822/9931.

Nóvon, A. (1987). Do Mestre-Escola ao Professor do Ensino Primário. Análise Psicológica, $3(\mathrm{~K})$, Lisboa: ISPA, pp. 413-440. 

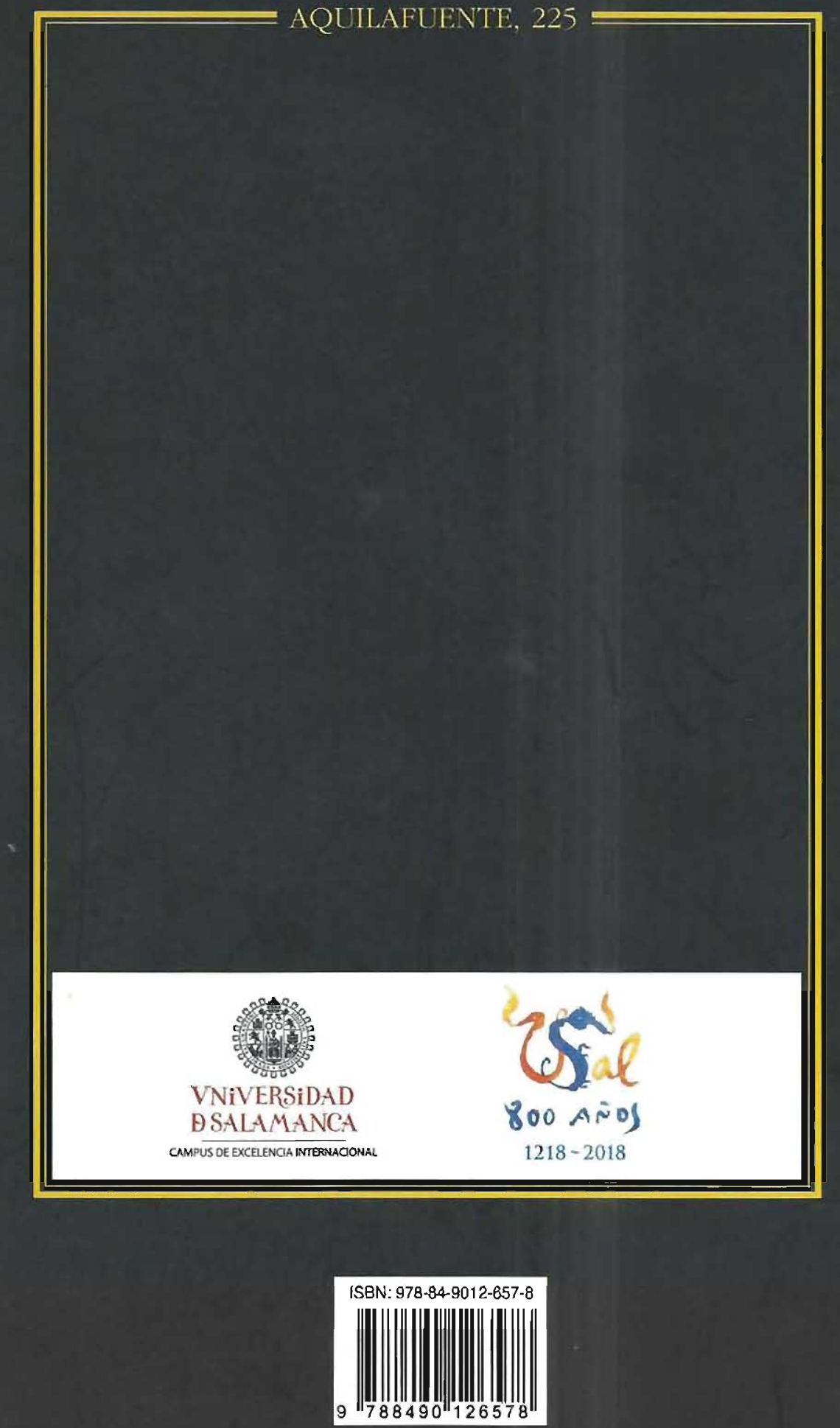